\title{
Inhibitor clinical burden of disease: a comparative analysis of the CHESS data
}

\author{
Abiola O. Oladapo ${ }^{1 *}$, Mei Lu', Shaun Walsh², Jamie O'Hara ${ }^{3}$ and Teresa L. Kauf ${ }^{4}$
}

\begin{abstract}
Background: Patients with hemophilia and inhibitors generally face greater disease burden compared to patients without inhibitors. While raising awareness of relative burden may improve the standard of care for patients with inhibitors, comparative data are sparse. Analyzing data drawn from the Cost of Haemophilia across Europe - a Socioeconomic Survey (CHESS) study, the aim of this study was to compare the clinical burden of disease in patients with severe hemophilia with and without inhibitors. Hemophilia specialists $(N=139)$ across five European countries completed an online survey between January-April 2015, providing demographic, clinical and 12-month ambulatory/secondary care activity data for 1285 patients. Patients with hemophilia who currently presented with inhibitors and those who never had inhibitors were matched on baseline characteristics via propensity score matching. Outcomes were compared between the two cohorts using a paired t-test or Wilcoxon signed-rank or McNemar's test.

Results: The proportion of patients who currently presented with inhibitors was 4.5\% (58/1285). Compared to PSmatched patients without inhibitors, patients with inhibitors experienced more than twice the mean annual number of bleeds (mean \pm standard deviation, $8.29 \pm 9.18$ vs $3.72 \pm 3.95 ; p<.0001)$ and joint bleeds $(2.17 \pm 1.90$ vs $0.98 \pm 1.15$; $p<.0001$ ), and required more hemophilia-related (mean \pm standard deviation, $1.79 \pm 1.83$ vs $0.64 \pm 1.13$ ) and bleed-related hospitalizations (1.86 \pm 1.88 vs $0.81 \pm 1.26$ ), hemophilia-related consultations ( $9.30 \pm 4.99$ vs $6.77 \pm 4.47$ ), and outpatient visits (22.09 \pm 17.77 vs $11.48 \pm 16.00)$ (all, $p<.001)$. More than one-half (53.5\%) experienced moderate/ severe pain necessitating medication compared to one-third (32.8\%) of patients without inhibitors $(p=.01)$.

Conclusions: Patients with hemophilia and inhibitors exhibited greater clinical burden and higher resource utilization compared to their peers without inhibitors. Strategies for improving the standard of care may alleviate burden in this population.
\end{abstract}

Keywords: Hemophilia, Inhibitors, Disease burden

\section{Background}

Congenital hemophilia is a life-long, X-linked hereditary bleeding disorder caused by the deficiency of coagulation factor VIII (FVIII) (hemophilia A) or factor IX (FIX) (hemophilia B) [1]. More than 400,000 individuals are afflicted globally [2] among whom, depending on the population, approximately $33 \%$ to $50 \%$ have severe hemophilia (FVIII or FIX activity level $<1 \%$ of normal) [3]. Severe hemophilia typically manifests during childhood or adolescence, peak periods of growth and psychosocial development, and is clinically characterized by a

\footnotetext{
* Correspondence: Abiola.Oladapo@shire.com

${ }^{1}$ Outcomes Research \& Epidemiology, Shire, 650 E Kendall Street, Cambridge, MA 02142, USA

Full list of author information is available at the end of the article
}

heightened risk for recurrent, spontaneous bleeding into the joints and muscles $[1,4]$. Without adequate management, patients can suffer significant morbidity due to the development of chronic arthropathy, disability, and impaired health-related quality of life (HRQoL). Additionally, patients with severe hemophilia can sustain substantial societal losses owing to decreased school/work participation, diminished productivity, and increased caregiver burden [5-7]. The Social Economic Burden and Health-Related Quality of Life of Patients with Rare Diseases (BURQOL-RD) study recently examined a cross-section of patients with hemophilia $(N=339)$ and caregivers $(N=62)$ in Europe and found that $40 \%$ of patients reported some degree of physical disability (Barthel Index score $\geq 91$ ), and over half (58.9\%) of caregivers felt burdened [8]. 
Advancements in hemophilia care have yielded factor replacement therapies, such as recombinant anti-hemophilia FVIII and recombinant FIX, which when administered prophylactically are efficacious in preventing or reducing the risk of bleeding and serious bleeding complications, preserving joint function, and improving HRQoL and productivity in patients with severe hemophilia [9-14]. Following exposure to exogenous FVIII/FIX, however, approximately $10-30 \%$ of patients with severe hemophilia A and $2-5 \%$ of those with severe hemophilia B develop alloantibodies to FVIII and FIX, respectively [15]. These inhibitors neutralize the coagulant activity of infused FVIII or FIX, rendering patients refractory to standard factor replacement therapy.

The development of a high-titer inhibitor ( $>5$ Bethesda units) in particular poses significant treatment challenges as achieving hemostasis becomes difficult with the administration of FVIII or FIX concentrates, necessitating the use of bypassing agents to control and prevent bleeding episodes. Current clinical guidance supports treatment with bypassing agents prophylaxis (BAP) in patients with severe hemophilia and inhibitors given its benefits over on-demand treatment [16]. Compared to on-demand treatment only, BAP reduces the frequency of joint bleeds, prevents the development of new target joints, reduces hospital admissions and school/work absences, and improves HRQoL [17-22]. However, despite the benefits of prophylaxis, and contrary to standard of care for patients without inhibitors, the majority of patients with inhibitors are still managed on-demand [23-25]. While it is generally accepted that patients with inhibitors face a higher disease burden compared to patients without inhibitors, limited comparative data exist in the literature to further raise awareness of the crucial need to improve the standard of care for these patients relative to their peers without inhibitors [26].

In this study, we used patient-level data from the Cost of Haemophilia across Europe - a Socioeconomic Survey (CHESS) study [27] to compare bleed rates and health resource utilization (HRU) in patients with severe hemophilia with and without inhibitors. As frequent evaluation of disease burden may assist in prioritizing and improving patient care [23], the objective was to quantify the real-world clinical burden of inhibitors in this contemporary population with severe hemophilia.

\section{Methods}

\section{Data collection}

The CHESS study was conducted by the University of Chester in partnership with the Haemophilia Society (United Kingdom). The CHESS Steering Committee, a collaboration of treating clinicians, patients with hemophilia, and representatives from academia and hemophilia societies, provided governance and oversight to ensure high standards of quality. As such, the CHESS study represents the first comprehensive, 'bottom-up' cost-of-illness study that captured data from approximately $15 \%$ of patients with severe hemophilia across five European countries (EU5) - France, Germany, Italy, Spain, and the United Kingdom. Its aim was to quantify the real-world societal costs of severe hemophilia (factor level of $<1 \%$ ) in the EU5 as a basis for understanding the potential impact of new hemophilia treatments.

Between January and April 2015, a cross-section of 139 hemophilia specialists completed an on-line survey and provided demographic, clinical, and 12-month retrospective ambulatory and secondary care activity data for adult males ( $>18$ years) with severe hemophilia A $(N=$ 996) or B $(N=289)$. Of the 1285 patients, 551 filled out corresponding questionnaires and disclosed information on out-of-pocket expenses and HRU. All patient-level data were anonymized. The current analysis was restricted to the patients and outcomes specified herein. Outcome variables for the analysis were defined a priori and were determined based on input from expert hematologists and the hemophilia literature.

\section{Identification of patients with and without inhibitors}

The present analysis included the CHESS patients who currently presented with inhibitors and those who had never had an inhibitor. Patients with inhibitors were identified from affirmative physician responses to the query, "Is the patient currently diagnosed with an inhibitor?" For patients without inhibitors, physicians responded 'Never' to the question, "How many times has the patient developed an inhibitor to factor replacement therapies over their lifetime?"

\section{Physician-reported information}

Physicians provided data on patient demographics and clinical characteristics (hemophilia type and comorbidities), 12-month bleed rates (including major, minor, and joint bleeds), and the current status of the patient's hemophilia-related chronic pain. Comorbidities of interest were selected by the CHESS Steering Committee. Minor bleeds were defined as bleeds resolving within $24 \mathrm{~h}$ of treatment and associated with mild pain, minimal swelling and restriction of motion. Bleeds failing to respond to treatment within $24 \mathrm{~h}$ and causing pain, effusion, and limitation of motion were considered major bleeds. The patient's current pain level was described as: 1) No pain: no functional deficit, no analgesic use (except with acute hemarthrosis); 2) Mild pain: does not interfere with occupation nor with activities of daily living (ADL), may require occasional non-narcotic analgesic; 3) Moderate pain: partial or occasional interference with occupation or ADL, uses non-narcotic medications; or 4) Severe pain: interferes with occupation or $\mathrm{ADL}$, requires frequent use of 
non-narcotic and narcotic medications. Physicians indicated their current satisfaction with the patient's prognosis by selecting 1 of 3 responses: 1) Satisfied; 2) Not satisfied, but I believe this is the best that can be realistically achieved for this patient; or 3) Not satisfied, and I believe better outcomes can be achieved for this patient.

\section{Health resource utilization}

Physicians reported the patient's frequency of HRU over the past 12 months, including hemophilia-related scheduled and non-scheduled consultations, hemophilia- and non-hemophilia-related outpatient visits, and hemophiliaand bleed-related hospitalizations. 'Hemophilia-related' services pertained to treatment for hemophilia complications or acute events, or planned surgeries.

\section{Statistical analysis}

Statistical analyses were performed using SAS 9.3 (SAS Institute Inc., Cary, NC, US). Baseline patient demographics, clinical attributes, and outcome measures were summarized descriptively as the mean \pm standard deviation (SD) and median (range) for continuous variables and frequency (percentage) for categorical variables. The two study cohorts (i.e. inhibitors and non-inhibitors) were matched using propensity score (PS) matching. In the PS matching, a logistic regression model was used to predict the odds for each patient to be enrolled in the inhibitor cohort, given patient characteristics (e.g. age, body mass index, comorbidity). Age and body mass index were treated as independent, continuous variables while race was dichotomized as either white or non-white. Each comorbidity variable was introduced into the model as a dichotomous variable. A greedy propensity score matching approach, utilizing the smaller caliper width that maintained the maximum sample size (caliper size of 0.035 ), was used to match a patient in the inhibitor cohort to a patient in the non-inhibitor cohort who had the closest propensity score within the specified caliper size and having the same type of hemophilia (hemophilia A or B). To determine if balance was achieved between the matched groups, differences between the matched pairs were evaluated for each baseline variable using a paired t-test or signed-rank test for continuous data and the McNemar's test for binary data. Finally, to address the study objective, matched cohorts were then compared on each outcome variable using a paired t-test or the Wilcoxon signed-rank test for continuous variables and the McNemar's test or exact McNemar's test for categorical variables. A two-tailed $p$-value $<0.05$ was considered statistically significant.

\section{Results}

Baseline demographics and clinical characteristics Fifty-eight (4.5\%) of the 1285 CHESS patients currently had an inhibitor, and 1091 (84.9\%) had never developed an inhibitor (Table 1). The remaining patients (10.6\%) used to but no longer have inhibitors. Among the 1149 patients (i.e. those that currently have or never had inhibitors), the mean age was $35.5 \pm 14.82$ years; $87.6 \%$ were white. Overall, $61.8 \%$ of patients were employed full-time; $3.0 \%$ were either unable to work or were currently on a temporary leave of absence due to their hemophilia. Nearly half (49\%) of the patients had at least one comorbidity of which, anxiety was most common (14.1\%), followed by depression (13.1\%), and hypertension $(12.1 \%)$.

In the unmatched cohorts, patients with inhibitors were older (mean age, $41.90 \pm 14.95$ years vs $35.16 \pm 14.74$ years; $p<.0002)$ and had significantly higher frequencies of anemia $(p=.0135)$, diabetes mellitus $(p=.0084)$, fibromyalgia $(p=.0034)$, hypertension $(p=.0134)$, and osteoarthritis $(p=.0175)$. Among the patients with relevant data, a significantly greater proportion of patients with inhibitors had attended college/graduate school $(46.2 \%[12 / 26]$ vs $38.1 \%$ [168/441], respectively; $p<.0001$ ); however, fewer patients with inhibitors worked full-time $(28.6 \%$ [8/28] vs $38.8 \%[174 / 449] ; p<.0001)$. Following PS matching (Table 2), the demographic and clinical attributes appeared statistically balanced between the cohorts (each, $N=58$ ).

\section{Bleeding outcomes following PS-matching}

In the PS-matched analysis (Table 3), the mean annualized bleed rate (ABR) in patients with inhibitors was more than doubled that in patients without inhibitors $(8.29 \pm 9.18$ vs $3.72 \pm 3.95 ; p<.0001) ; 81 \%$ of patients with inhibitors had experienced a major bleed (vs $37.9 \%$ of patients without inhibitors; $p<.0001$ ), and all patients with inhibitors (100\%) had minor bleeds (vs $82.8 \%$ of patients without inhibitors; $p=.0047)$. Similarly, the mean annualized joint bleed rate (AJBR) in patients with inhibitors exceeded that in patients without inhibitors by more than two-fold $(2.17 \pm 1.90$ vs $0.98 \pm 1.15 ; \mathrm{p}<.0001) ; 93.1 \%$ of patients with inhibitors experienced joint bleeds during the 12 months compared to $55.2 \%$ of patients without inhibitors $(p<.0001)$. Chronic hemophilia-related pain was more prevalent and significantly worse in the cohort with inhibitors (Fig. 1). Moderate or severe chronic pain was reported in more than half (53.4\%) of patients with inhibitors and in about one-third (32.8\%) of patients without inhibitors $(p=.0105)$. Outcomes in the unmatched cohorts, including bleeding events, are shown in Additional file 1.

\section{Health resource utilization}

Fifty-six matched pairs contributed data to the analysis of HRU. Over 12 months, patients with inhibitors had consulted with hemophilia specialists significantly more often than patients without inhibitors (mean, $9.30 \pm 4.99$ vs 6.77 \pm 4.47 visits; $p=.0045$ ). In addition, patients with inhibitors had significantly higher outpatient visits (mean, 22.09 
Table 1 Baseline characteristics of CHESS sample with severe hemophilia and unmatched cohorts with and without inhibitors

\begin{tabular}{|c|c|c|c|c|}
\hline \multirow[t]{2}{*}{ Characteristic } & All patients & $\begin{array}{l}\text { Patients who never developed } \\
\text { inhibitors }\end{array}$ & $\begin{array}{l}\text { Patients with current } \\
\text { inhibitors }\end{array}$ & \multirow[t]{2}{*}{$p$-value ${ }^{a}$} \\
\hline & $N=1149$ & $N=1091$ & \multirow{2}{*}{\multicolumn{2}{|c|}{$N=58$}} \\
\hline \multicolumn{3}{|l|}{ Demographics } & & \\
\hline \multicolumn{5}{|l|}{ Age, years } \\
\hline Mean \pm SD & $35.50 \pm 14.82$ & $35.16 \pm 14.74$ & $41.90 \pm 14.95$ & \multirow[t]{2}{*}{.0002} \\
\hline Median (range) & $32(18.00-88.00)$ & $31(18.00-88.00)$ & $39.5(18.00-80.00)$ & \\
\hline \multicolumn{5}{|l|}{ Race, N (\%) } \\
\hline White & 1007 (87.6) & $958(87.8)$ & $49(84.5)$ & \multirow[t]{6}{*}{.6260} \\
\hline African & $50(4.4)$ & $48(4.4)$ & $2(3.4)$ & \\
\hline Asian-Indian subcontinent & $37(3.2)$ & $34(3.1)$ & $3(5.2)$ & \\
\hline Asian-Other & $6(0.5)$ & $6(0.5)$ & $0(0.0)$ & \\
\hline Middle Eastern & $46(4.0)$ & $42(3.8)$ & $4(6.9)$ & \\
\hline Other & $3(0.3)$ & $3(0.3)$ & $0(0.0)$ & \\
\hline White & 1007 (87.6) & $958(87.8)$ & $49(84.5)$ & \multirow[t]{2}{*}{.4532} \\
\hline Non-white & $142(12.4)$ & $133(12.2)$ & $9(15.5)$ & \\
\hline \multicolumn{5}{|l|}{ Body mass index } \\
\hline Mean \pm SD & $24.76 \pm 3.25$ & $24.73 \pm 3.27$ & $25.31 \pm 2.78$ & \multirow[t]{2}{*}{.1140} \\
\hline Median (range) & $24.57(14.11-57.47)$ & $24.51(14.11-57.47)$ & $25(20.52-32.83)$ & \\
\hline \multicolumn{5}{|l|}{ Education, N (\%) } \\
\hline None & $15(1.3)$ & $12(1.1)$ & $3(5.2)$ & \\
\hline Primary & $51(4.4)$ & $49(4.5)$ & $2(3.4)$ & \\
\hline Secondary & $8(0.7)$ & $8(0.7)$ & $0(0.0)$ & \\
\hline Undergraduate & $76(6.6)$ & $73(6.7)$ & $3(5.2)$ & \\
\hline Graduate & $203(17.7)$ & $192(17.6)$ & $11(19.0)$ & \\
\hline Did not answer & $129(11.2)$ & $119(10.9)$ & $10(17.2)$ & \\
\hline \multicolumn{5}{|l|}{ College or graduate } \\
\hline Yes & $180(38.5)$ & $168(38.1)$ & $12(46.2)$ & \multirow[t]{2}{*}{$<.0001$} \\
\hline No & $287(61.5)$ & $273(61.9)$ & $14(53.8)$ & \\
\hline \multicolumn{5}{|l|}{ Employment status, N (\%) } \\
\hline Full-time employed & $182(15.8)$ & $174(15.9)$ & $8(13.8)$ & \\
\hline Homemaker & $1(0.1)$ & $1(0.1)$ & $0(0.0)$ & \\
\hline Self-employed & $3(0.3)$ & $1(0.1)$ & $2(3.4)$ & \\
\hline Other: Not determined/not specified & $4(0.4)$ & $4(0.4)$ & $0(0.0)$ & \\
\hline Part-time employed & $74(6.4)$ & $68(6.2)$ & $6(10.3)$ & \\
\hline Retired & $46(4.0)$ & $42(3.8)$ & $4(6.9)$ & \\
\hline Student & $84(7.3)$ & $82(7.5)$ & $2(3.4)$ & \\
\hline Temporary leave of absence due to my hemophilia & $6(0.5)$ & $5(0.5)$ & $1(1.7)$ & \\
\hline Temporary leave of absence due to other reason(s) & $6(0.5)$ & $6(0.5)$ & $0(0.0)$ & \\
\hline Unable to work due to my hemophilia & $29(2.5)$ & $23(2.1)$ & $6(10.3)$ & \\
\hline Unable to work due to other reason(s) & $2(0.2)$ & $2(0.2)$ & $0(0.0)$ & \\
\hline Unemployed, able to work & $40(3.5)$ & $40(3.7)$ & $0(0.0)$ & \\
\hline \multicolumn{5}{|l|}{ Full-time employed } \\
\hline Yes & $182(38.2)$ & $174(38.8)$ & $8(28.6)$ & \multirow[t]{2}{*}{$<.0001$} \\
\hline No & $295(61.8)$ & $275(61.2)$ & $20(71.4)$ & \\
\hline
\end{tabular}


Table 1 Baseline characteristics of CHESS sample with severe hemophilia and unmatched cohorts with and without inhibitors (Continued)

\begin{tabular}{|c|c|c|c|c|}
\hline \multirow[t]{2}{*}{ Characteristic } & \multirow{2}{*}{$\begin{array}{l}\text { All patients } \\
N=1149\end{array}$} & \multirow{2}{*}{$\begin{array}{l}\text { Patients who never developed } \\
\text { inhibitors } \\
N=1091\end{array}$} & \multirow{2}{*}{$\begin{array}{l}\text { Patients with current } \\
\text { inhibitors } \\
N=58\end{array}$} & \multirow[t]{2}{*}{$p$-value } \\
\hline & & & & \\
\hline \multicolumn{5}{|l|}{ Hemophilia type, $N(\%)$} \\
\hline Hemophilia A & $894(77.8)$ & 847 (77.6) & $47(81.0)$ & \multirow[t]{2}{*}{.5438} \\
\hline Hemophilia B & $255(22.2)$ & $244(22.4)$ & $11(19.0)$ & \\
\hline \multicolumn{5}{|l|}{ Comorbidities, N (\%) } \\
\hline None & $586(51.0)$ & $578(53.0)$ & $8(13.8)$ & $<.0001$ \\
\hline Alcohol dependence & $39(3.4)$ & $35(3.2)$ & $4(6.9)$ & .1291 \\
\hline Anemia & $65(5.7)$ & $57(5.2)$ & $8(13.8)$ & .0135 \\
\hline Anxiety & $162(14.1)$ & $150(13.7)$ & $12(20.7)$ & .1389 \\
\hline Depression & $151(13.1)$ & $140(12.8)$ & $11(19.0)$ & .1779 \\
\hline Diabetes mellitus & $60(5.2)$ & $52(4.8)$ & $8(13.8)$ & .0084 \\
\hline Fibromyalgia & $41(3.6)$ & $34(3.1)$ & $7(12.1)$ & .0034 \\
\hline Hepatitis B virus & $20(1.7)$ & $19(1.7)$ & $1(1.7)$ & 1.0000 \\
\hline Hepatitis C virus & $61(5.3)$ & $56(5.1)$ & $5(8.6)$ & .2282 \\
\hline Human immunodeficiency virus & $31(2.7)$ & $28(2.6)$ & $3(5.2)$ & .2028 \\
\hline Hypertension & $139(12.1)$ & $126(11.5)$ & $13(22.4)$ & .0134 \\
\hline Hypercholesterolemia & $70(6.1)$ & $65(6.0)$ & $5(8.6)$ & .3931 \\
\hline Ischemic heart disease & $19(1.7)$ & $16(1.5)$ & $3(5.2)$ & .0665 \\
\hline Obesity & $63(5.5)$ & $60(5.5)$ & $3(5.2)$ & 1.0000 \\
\hline Osteoarthritis & $68(5.9)$ & $60(5.5)$ & $8(13.8)$ & .0175 \\
\hline Osteoporosis & $11(1.0)$ & $11(1.0)$ & $0(0.0)$ & 1.0000 \\
\hline Rheumatoid arthritis & $9(0.8)$ & $9(0.8)$ & $0(0.0)$ & 1.0000 \\
\hline Other & $18(1.6)$ & $16(1.5)$ & $2(3.4)$ & .2293 \\
\hline
\end{tabular}

Abbreviations: CHESS, Cost of Haemophilia across Europe - a Socioeconomic Survey; SD, standard deviation

${ }^{a} P$-values were derived from a paired t-test or Wilcoxon signed rank test for continuous post-match variables and the McNemar's test or exact McNemar's test for categorical variables; $p<.05$ indicates statistical significance

\pm 17.77 vs $11.48 \pm 16.00 ; p=.0001)$, hemophilia-related $(1.79 \pm 1.83$ vs $0.64 \pm 1.13 ; p<.0001)$ and bleed-related admissions $(1.86 \pm 1.88$ vs $0.81 \pm 1.26 ; p=.0003)$ compared to their peers without inhibitors (Fig. 2).

\section{Physician satisfaction}

Among the physicians of patients without inhibitors, $39.7 \%(23 / 58)$ were currently dissatisfied with their patient's prognosis, of whom, $65.2 \%(15 / 23)$ believed that an optimal prognosis had been attained, and $34.8 \%(8 / 23)$ opined that better outcomes could be achieved. In contrast, $43.1 \%(25 / 58)$ of physicians of patients with inhibitors were dissatisfied with the patient's prognosis (Table 4).

\section{Discussion}

Over the past decade, prophylactic factor replacement therapy has emerged as the standard of care for patients with severe hemophilia in developed countries where access to factor concentrates is unimpeded [28]. Still, the development of an inhibitor remains universally, the most serious treatment complication that poses a significant barrier to successful care [15, 29-32]. Assessing the burden of inhibitors in a contemporary population with severe hemophilia may therefore provide insight into the effectiveness of current treatment approaches, raise awareness of unmet needs, and assist in improving patient care.

Real-world patient-level data from the CHESS study afforded the opportunity to quantify the clinical burden of inhibitors in a cross-section of 1285 patients representing approximately $15 \%$ of the population with severe hemophilia in the EU5 [27]. The prevalence of current inhibitors was $4.5 \%$, which approached published estimates (5-7\%) for the hemophilia population, but was lower than that for patients with severe hemophilia (1213\%) [33]. Of the 1285 patients, 136 (10.6\%) patients had inhibitors in the past and did not currently present with inhibitors. Considering that $84.9 \%$ of the CHESS sample had never developed inhibitors, the cumulative percentage with current and past inhibitors was 15.1\%, which more closely approximated the cited range. 
Table 2 Baseline characteristics of PS-matched patients with and without inhibitors in the CHESS study ${ }^{\text {a }}$

\begin{tabular}{|c|c|c|c|}
\hline \multirow[t]{2}{*}{ Characteristic } & Patients who never developed inhibitors & Patients with current inhibitors & $p$-value \\
\hline & $N=58$ & \multicolumn{2}{|l|}{$N=58$} \\
\hline \multicolumn{4}{|l|}{ Demographics } \\
\hline \multicolumn{4}{|l|}{ Age, years } \\
\hline Mean \pm SD & $43.71 \pm 17.17$ & $41.90 \pm 14.95$ & \multirow[t]{2}{*}{.4800} \\
\hline Median (range) & $43(18.00-88.00)$ & $39.5(18.00-80.00)$ & \\
\hline \multicolumn{4}{|l|}{ Race, $N(\%)$} \\
\hline White & $43(74.1)$ & $49(84.5)$ & .1573 \\
\hline \multicolumn{4}{|l|}{ Body mass index } \\
\hline Mean \pm SD & $24.92 \pm 2.67$ & $25.31 \pm 2.78$ & \multirow[t]{2}{*}{.4072} \\
\hline Median (range) & $25.08(15.57-32.02)$ & $25.00(20.52-32.83)$ & \\
\hline \multicolumn{4}{|l|}{ Hemophilia type, $N(\%)$} \\
\hline Hemophilia A & $47(81.0)$ & $47(81.0)$ & 1.0000 \\
\hline \multicolumn{4}{|l|}{ Comorbidities, N (\%) } \\
\hline Alcohol dependence & $7(12.1)$ & $4(6.9)$ & .3173 \\
\hline Anemia & $6(10.3)$ & $8(13.8)$ & .5271 \\
\hline Anxiety & $13(22.4)$ & $12(20.7)$ & .8415 \\
\hline Depression & $13(22.4)$ & $11(19.0)$ & .6374 \\
\hline Diabetes mellitus & $7(12.1)$ & $8(13.8)$ & .7389 \\
\hline Fibromyalgia & $3(5.2)$ & $7(12.1)$ & .1573 \\
\hline Hepatitis $B$ virus & $1(1.7)$ & $1(1.7)$ & 1.0000 \\
\hline Hepatitis C virus & $9(15.5)$ & $5(8.6)$ & .2850 \\
\hline Human immunodeficiency virus & $8(13.8)$ & $3(5.2)$ & .0956 \\
\hline Hypertension & $15(25.9)$ & $13(22.4)$ & .6374 \\
\hline Hypercholesterolemia & $7(12.1)$ & $5(8.6)$ & .5271 \\
\hline Ischemic heart disease & $4(6.9)$ & $3(5.2)$ & .7055 \\
\hline Obesity & $1(1.7)$ & $3(5.2)$ & .3173 \\
\hline Osteoarthritis & $7(12.1)$ & $8(13.8)$ & .7815 \\
\hline
\end{tabular}

Abbreviations: BMI body mass index, CHESS Cost of Haemophilia across Europe - a Socioeconomic Survey, PS propensity score, SD standard deviation ${ }^{\text {a }}$ Patients with current inhibitors were matched to patients who had never developed an inhibitor based on demographics (age, BMI, race) and comorbidity status using propensity scores stratified by hemophilia type. Matching was performed using a preset caliper size of 0.035 to maintain the maximum sample size using the smallest caliper width

${ }^{b} P$-values were derived from a paired t-test or Wilcoxon signed rank test for continuous post-match variables and the McNemar's test or exact McNemar's test for categorical variables; $p<.05$ indicates statistical significance

Consistent with other literature [34,35], comorbidities were prevalent in nearly half $(49 \%$; $563 / 1149)$ of the total unmatched sample of all patients with hemophilia. Notably, the frequency of hypertension, which has been associated with intracranial hemorrhage and atrial fibrillation in patients with hemophilia [36, 37], was significantly higher in the inhibitor cohort (22\% vs $11.5 \% ; p=.0134)$. This may have been due to the more advanced age of the patients with inhibitors (mean, 41.9 vs 35.2 years) as age-related conditions manifest over time.

In the PS-matching analysis, patients with inhibitors were considerably more burdened compared to patients without inhibitors as evidenced by a more than two-fold increase in both the overall mean ABR and mean AJBR. Over 12 months, the vast majority of patients with inhibitors had experienced major bleeds (81\%) and joint bleeds (93\%). Compared to patients without inhibitors, patients with inhibitors required not only significantly more hemophilia- and bleed-related hospitalizations, but more unscheduled visits with hemophilia specialists and non-hemophilia-related outpatient visits. More than half (53.5\%) experienced chronic pain interference necessitating analgesic medication. The significantly higher bleed rates in this cohort may have reflected the standard of care in the inhibitor population which may have been primarily focused on the on-demand or acute management of bleeds. Although this remains to be confirmed by examining treatment patterns in the CHESS study, the finding that more than one-third $(39.7 \%)$ of physicians of inhibitor patients were dissatisfied with the 
Table 3 Frequency of bleeds in PS-matched patients with and without inhibitors in the CHESS study ${ }^{\mathrm{a}}$

\begin{tabular}{|c|c|c|c|}
\hline \multirow[t]{2}{*}{ Outcomes } & Patients who never developed inhibitors & Patients with current inhibitors & \multirow[t]{2}{*}{$p$-value } \\
\hline & $N=58$ & $N=58$ & \\
\hline \multicolumn{4}{|c|}{$\begin{array}{l}\text { Bleeds in the past } 12 \text { months } \\
\text { (major and minor bleeds) }\end{array}$} \\
\hline Mean \pm SD & $3.72 \pm 3.95$ & $8.29 \pm 9.18$ & \multirow[t]{2}{*}{$<.0001$} \\
\hline Median (range) & $3(0.00-18.00)$ & $6(1.00-60.00)$ & \\
\hline \multicolumn{4}{|l|}{ Major bleeds, N (\%) } \\
\hline Yes & $22(37.9)$ & $47(81.0)$ & \multirow[t]{2}{*}{$<.0001$} \\
\hline No & $36(62.1)$ & $11(19.0)$ & \\
\hline \multicolumn{4}{|l|}{ Minor bleeds, N (\%) } \\
\hline Yes & $48(82.8)$ & $58(100.0)$ & \multirow[t]{2}{*}{.0047} \\
\hline No & $10(17.2)$ & $0(0.0)$ & \\
\hline \multicolumn{4}{|c|}{ Joint bleeds in past 12 months } \\
\hline Mean $\pm S D$ & $0.98 \pm 1.15$ & $2.17 \pm 1.90$ & \multirow[t]{2}{*}{$<.0001$} \\
\hline Median (range) & $1(0.00-4.00)$ & $2(0.00-8.00)$ & \\
\hline Yes, $N(\%)$ & $32(55.2)$ & $54(93.1)$ & \multirow[t]{2}{*}{$<.0001$} \\
\hline No, $N(\%)$ & $26(44.8)$ & $4(6.9)$ & \\
\hline
\end{tabular}

$B M I$ body mass index, CHESS Cost of Haemophilia across Europe - a Socioeconomic Survey, PS propensity score, SD standard deviation

a Patients with current inhibitors were matched to patients who had never developed an inhibitor based on demographics (age, BMl, race) and comorbidity status using propensity scores stratified by hemophilia type. Matching was performed using a preset caliper size of 0.035 to maintain the maximum sample size using the smallest caliper width

${ }^{\mathrm{b}} P$-values were derived from a paired t-test or Wilcoxon signed rank test for continuous post-match variables and the McNemar's test or exact McNemar's test for categorical variables; $p<.05$ indicates statistical significance. The McNemar's test was not conducted for minor bleeds due to occurrence of event in $100 \%$ of inhibitor cohort

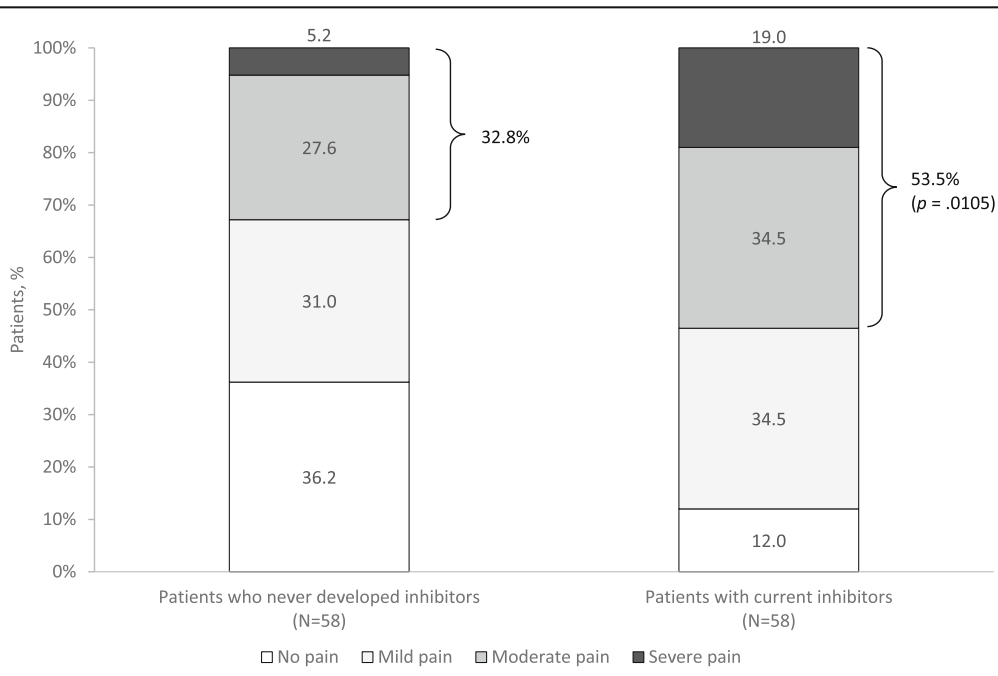

Fig. 1 Physician-reported chronic hemophilia-pain by severity for PS-matched patients with and without inhibitors in CHESS study ${ }^{\mathrm{a}}$. ${ }^{\mathrm{P}}$ atients with current inhibitors were matched to patients who had never developed an inhibitor based on demographics (age, BMI, race) and comorbidity status using propensity scores stratified by hemophilia type. Matching was performed using a preset caliper size of 0.035 to maintain the maximum sample size using the smallest caliper width. ${ }^{b} P$-value refers to the difference in the proportion of patients with moderate to severe pain between cohorts and was derived from the McNemar's test for categorical variables; $p<.05$ indicates statistical significance. Abbreviations: BMl, body mass index; CHESS, Cost of Haemophilia across Europe - a Socioeconomic Survey; PS, propensity score 

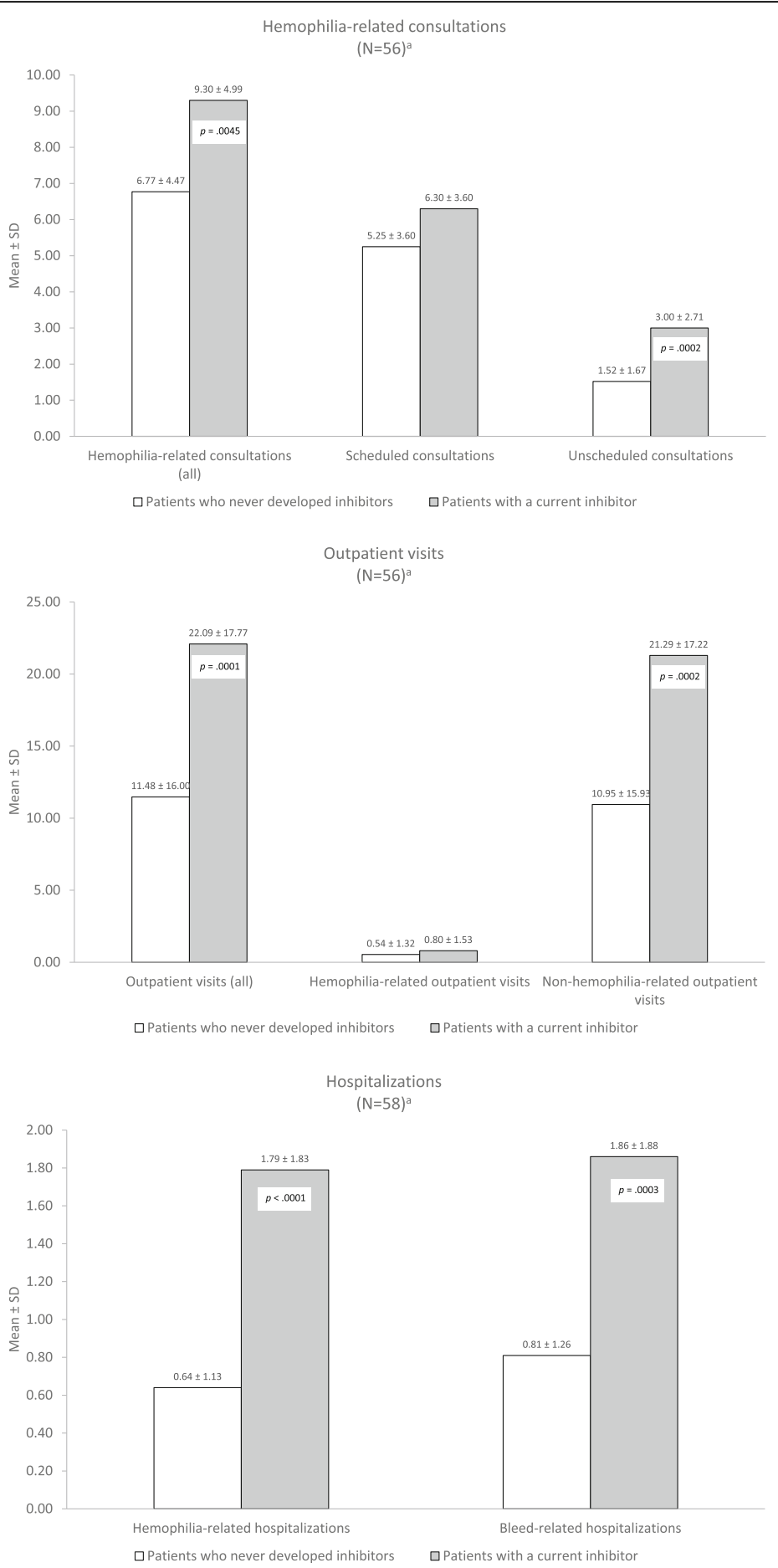

Fig. 2 HRU frequency over 12 months for PS-matched patients with and without inhibitors in CHESS study ${ }^{a}$. ${ }^{\prime} N^{\prime}$ pertains to number of patients in each cohort after PS-matching. Patients with current inhibitors were matched to patients who had never developed an inhibitor based on demographics (age, BMI, race) and comorbidity status using propensity scores stratified by hemophilia type. Matching was performed using a preset caliper size of 0.035 to maintain the maximum sample size using the smallest caliper width. ${ }^{b} P$-values were derived from a paired t-test or Wilcoxon signed rank test for continuous post-match variables; $p<.05$ indicates statistical significance. Abbreviations: BMI, body mass index; CHESS, Cost of Haemophilia across Europe - a Socioeconomic Survey; HRU, health resource utilization; PS, propensity score; SD, standard deviation 
Table 4 Physician-reported satisfaction regarding PS-matched patients with and without inhibitors in the CHESS study ${ }^{a}$

\begin{tabular}{|c|c|c|c|}
\hline \multirow[t]{2}{*}{ Outcomes } & $\begin{array}{l}\text { Patients } \\
\text { who never } \\
\text { developed } \\
\text { inhibitors }\end{array}$ & $\begin{array}{l}\text { Patients } \\
\text { with current } \\
\text { inhibitors }\end{array}$ & \multirow[t]{2}{*}{$p$-value } \\
\hline & $N=58$ & $N=58$ & \\
\hline
\end{tabular}

Physician responses to question, "Which of the following best describes your current satisfaction with the prognosis for this haemophilia patient?" N (\%)

\begin{tabular}{lll}
$N$ & 58 & 58 \\
Satisfied & $35(60.3)$ & $33(56.9)$ \\
$\begin{array}{l}\text { Not satisfied, but I believe this is } \\
\text { the best that can be realistically }\end{array}$ & $15(25.9)$ & $14(24.1)$ \\
achieved for this patient & & \\
$\begin{array}{l}\text { Not satisfied, and I believe better } \\
\text { outcomes can be achieved for }\end{array}$ & $8(13.8)$ & $11(19.0)$ \\
this patient & $35(60.3)$ & $33(56.9)$ \\
$\begin{array}{l}\text { Satisfied } \\
\text { Not satisfied }\end{array}$ & $23(39.7)$ & $25(43.1)$ \\
\hline
\end{tabular}

Abbreviations: BMI body mass index, CHESS Cost of Haemophilia across Europe - a Socioeconomic Survey, PS propensity score

apatients with current inhibitors were matched to patients who had never developed an inhibitor based on demographics (age, BMI, race) and comorbidity status using propensity scores stratified by hemophilia type. Matching was performed using a preset caliper size of 0.035 to maintain the maximum sample size using the smallest caliper width

${ }^{\mathrm{b}} \mathrm{P}$-values were derived from a paired t-test or Wilcoxon signed rank test for continuous post-match variables, and the McNemar's test or exact McNemar's test for categorical variables; $p<.05$ indicates statistical significance

patient's prognosis may also attest to the particular challenge of managing adult patients with inhibitors.

The incremental clinical burden of inhibitors observed in the CHESS cohort mirrored the trends observed in the European Study on Orthopaedic Status of Haemophilia Patients (ESOS), a cross-sectional, case-control study of patients with hemophilia enrolled during the period from March 2004 to December 2005. In the ESOS, patients aged 14-35 years who had severe hemophilia with inhibitors $(N=38)$ had significantly worse joint pain $(p<.05)$, more mobility problems $(p<.001)$, and poorer orthopedic scores $(\mathrm{p}<.05)$ than patients without inhibitors $(N=49)$ [15]. Greater proportions of patients with inhibitors in the ESOS, irrespective of age, were also hospitalized for musculoskeletal bleeding or orthopedic procedures (16\% of patients aged 14-35 years and 27\% of patients aged 3665 years $[N=41])$ compared to patients without inhibitors (4\%). The mean AJBR was comparable between the inhibitor cohorts and controls, although patients with inhibitors had significantly worse orthopedic scores [15]. Although orthopedic status was not analyzed in the CHESS sample, the higher AJBR in the inhibitor cohort (vs non-inhibitor cohort) may nonetheless signify increased morbidity as chronic joint bleeds have been associated with a greater frequency of orthopedic complications [15]. Comparing orthopedic status and the associated HRU between the PS-matched CHESS samples in future research may more precisely quantify the burden of inhibitors in the contemporary hemophilia population.

Study limitations are noted. First, as in all questionnairebased research, the validity of the survey responses was subject to the respondents' interpretation, recall, and accuracy in recording information. However, this limitation pertains primarily to the patients' responses as the physicians provided data obtained from their retrospective chart reviews. Second, although we adjusted for baseline covariates, unmeasured confounding factors may have accounted for some differences in the outcomes between the PSmatched cohorts. However, the increased clinical burden of disease in the inhibitor cohort was consistent with observations in prior studies $[15,38,39]$. Third, due to the cross-sectional study design, the prevalence of current inhibitors represented a 'point-in-time' estimate which may have overestimated or underestimated the true burden of inhibitors. Further, we did not compare orthopedic status, which may have further differentiated the cohorts; however, a future analysis including this endpoint may be considered. Finally, although data were collected across the EU5, we did not conduct country-specific analyses due to the small sample size.

\section{Conclusions}

Patients with inhibitors in the CHESS study exhibited greater clinical burden and utilized significantly more health resources compared to their peers without inhibitors. Physician dissatisfaction with their patients' prognosis underscores the need for improving the standard of care for patients with inhibitors. Strategies for individualizing and improving care may also reduce the clinical burden of disease in this population.

\section{Additional file}

Additional file 1: Frequency of bleeds, physician-reported chronic hemophilia pain by severity, HRU frequency over 12 months, and physician-reported satisfaction for patients with severe hemophilia in a CHESS study sample of unmatched cohorts with and without inhibitors. (DOCX 36 kb)

\begin{abstract}
Abbreviations
ABR: Annualized bleed rate; ADL: Activities of daily living; AJBR: Annualized joint bleed rate; BAP: Bypassing agents prophylaxis; BURQOL-RD: Social Economic Burden and Health-Related Quality of Life of Patients with Rare Diseases; CHESS: Cost of Haemophilia across Europe - a Socioeconomic Survey; ESOS: European Study on Orthopaedic Status of Haemophilia Patients; FIX: Factor IX; FVIII: Factor VIII; HRQoL: Health-related quality of life; HRU: Health resource utilization; PS: Propensity score; SD: Standard deviation
\end{abstract}

\section{Acknowledgements}

Medical writing and editorial support were provided by Erin Williams, BSN, Marinus Consulting, LLC, (Palo Alto, CA, USA) and funded by Baxalta, part of Shire (Cambridge, MA, USA). 


\section{Funding}

The original CHESS research was supported by unrestricted research grants from Swedish Orphan Biovitrum AB (Sobi) and Novo Nordisk. Funding for the present analyses was provided by Baxalta, part of Shire (Cambridge, MA, USA).

\section{Availability of data and materials}

The CHESS study data are not available in the public domain, but may be accessed upon reasonable request and with appropriate permissions from the corresponding author.

\section{Authors' contributions}

$\mathrm{AO}, \mathrm{SW}, \mathrm{JOH}$, and TLK developed the study. ML and SW conducted the statistical analysis. All authors provided critical review and revisions of each draft and approved the final manuscript.

\section{Ethics approval and consent to participate}

The CHESS study received ethics approval from the University of Chester Ethics Committee. All patients or their legal representatives provided signed informed consent to participate in this study.

\section{Consent for publication}

Not applicable.

\section{Competing interests}

$\mathrm{AO}$ and $\mathrm{ML}$ are employees and shareholders of Shire. SW was an employee of HCD at the time the study was completed. TLK was an employee of Shire at the time the study was completed.

\section{Publisher's Note}

Springer Nature remains neutral with regard to jurisdictional claims in published maps and institutional affiliations.

\section{Author details}

'Outcomes Research \& Epidemiology, Shire, 650 E Kendall Street, Cambridge, MA 02142, USA. ${ }^{2}$ HCD Economics, Daresbury, UK. ${ }^{3}$ Faculty of Health and Social Care, University of Chester, Chester, UK. ${ }^{4}$ Shire, Zug, Switzerland.

Received: 8 May 2018 Accepted: 8 October 2018

Published online: 09 November 2018

\section{References}

1. Blanchette VS, Key NS, Ljung LR, Manco-Johnson MJ, van den Berg HM, Srivastava A, et al. Definitions in hemophilia: communication from the SSC of the ISTH. J Thromb Haemost. 2014:12(11):1935-9.

2. Skinner MW. WFH: closing the global gap--achieving optimal care. Haemophilia. 2012;18(Suppl 4):1-12.

3. World Federation of Hemophilia. Report on the Annual Global Survey 2015. October 2016. Available at: http://www1.wfh.org/publication/files/pdf-1669. pdf. Accessed October 19, 2016.

4. Young $G$. From boy to man: recommendations for the transition process in haemophilia. Haemophilia. 2012;18(Suppl 5):27-32.

5. Brown SA, Aledort LM. Economic challenges in haemophilia. Haemophilia. 2005;11(1):64-72.

6. Globe DR, Cunningham WE, Andersen R, Dietrich SL, Curtis RG, Parish KL, et al. The Hemophilia Utilization Group Study (HUGS): determinants of costs of care in persons with haemophilia A. Haemophilia. 2003;9(3):325-31.

7. Shapiro AD, Donfield SM, Lynn HS, Cool VA, Stehbens JA, Hunsberger SL, et al. Defining the impact of hemophilia: the Academic Achievement in Children with Hemophilia Study. Pediatrics. 2001:108(6):E105.

8. Carazza M, Kodra Y, Armeni P, De Santis M, Lopez-Bastida J, Linertova R, et al. Social/economic costs and quality of life in patients with haemophilia in Europe. Eur J Health Econ. 2016;17(Suppl 1):S53-65.

9. Nilsson IM, Berntorp E, Lofqvist T, Pettersson H. Twenty-five years' experience of prophylactic treatment in severe haemophilia A and B. Intern Med. 1992;232(1):25-32.

10. Gringeri A, Lundin B, von Mackensen S, Mantovani L, Mannucci PM. A randomized clinical trial of prophylaxis in children with hemophilia $A$ (the ESPRIT Study). J Thromb Haemost. 2011;9(4):700-10.

11. Manco-Johnson MJ, Abshire TC, Shapiro AD, Riske B, Hacker MR, Kilcoyne R, et al. Prophylaxis versus episodic treatment to prevent joint disease in boys with severe hemophilia. N Engl J Med. 2007;357(6):535-44.
12. Manco-Johnson MJ, Kempton CL, Reding MT, Lissitchkov T, Goranov S, Gercheva $L$, et al. Randomized, controlled, parallel-group trial of routine prophylaxis vs. on-demand treatment with sucrose-formulated recombinant factor VIII in adults with severe hemophilia A (SPINART). J Thromb Haemost. 2013;11(6):1119-27.

13. Tagliaferri A, Feola G, Molinari AC, Santoro C, Rivolta GF, Cultrera DB, et al. Benefits of prophylaxis versus on-demand treatment in adolescents and adults with severe haemophilia A: the POTTER study. Thromb Haemost. 2015:114(1):35-45

14. Oladapo AO, Epstein JD, Williams E, Ito D, Gringeri A, Valentino LA. Healthrelated quality of life assessment in haemophilia patients on prophylaxis therapy: a systematic review of results from prospective clinical trials. Haemophilia. 2015;21(5):e344-58.

15. Morfini M, Haya S, Tagariello G, Pollmann H, Quintana M, Siegmund B, et al. European study on orthopaedic status of haemophilia patients with inhibitors. Haemophilia. 2007;13(5):606-12.

16. National Hemophilia Foundation. MASAC Recommendation Regarding Prophylaxis with Bypassing Agents in Patients with Hemophilia and High Titer Inhibitors. MASAC Document \#220. October 5, 2013. https:// www.hemophilia.org/sites/default/files/document/files/masac220.pdf. Accessed 12 Oct 2018

17. Konkle BA, Ebbesen LS, Erhardtsen E, Bianco RP, Lissitchkov T, Rusen L, et al. Randomized, prospective clinical trial of recombinant factor VIla for secondary prophylaxis in hemophilia patients with inhibitors. J Thromb Haemost. 2007;5(9):1904-13.

18. Leissinger C, Gringeri A, Antmen B, Berntorp E, Biasoli C, Carpenter S, et al. Anti-inhibitor coagulant complex prophylaxis in hemophilia with inhibitors. N Engl J Med. 2011:365(18):1684-92.

19. Antunes SV, Tangada S, Stasyshyn O, Mamonov V, Phillips J, GuzmanBecerra N, et al. Randomized comparison of prophylaxis and on-demand regimens with FEIBA NF in the treatment of haemophilia $A$ and $B$ with inhibitors. Haemophilia. 2014:20(1):65-72.

20. Hoots WK, Ebbesen LS, Konkle BA, Auerswald GK, Roberts HR, Weatherall J, et al. Secondary prophylaxis with recombinant activated factor VII improves health-related quality of life of haemophilia patients with inhibitors. Haemophilia. 2008;14(3):466-75.

21. Gringeri A, Leissinger C, Cortesi PA, Jo H, Fusco F, Riva S, et al. Healthrelated quality of life in patients with haemophilia and inhibitors on prophylaxis with anti-inhibitor complex concentrate: results from the ProFEIBA study. Haemophilia. 2013;19(5):736-43.

22. Stasyshyn O, Antunes SV, Mamonov V, Ye X, Epstein JD, Xiong Y, et al. Prophylaxis with anti-inhibitor coagulant complex improves health-related quality of life in haemophilia patients with inhibitors: results from FEIBA NF prophylaxis study. Haemophilia. 2014;20(5):644-50

23. Zappa S, McDaniel M, Marandola J, Allen G. Treatment trends for haemophilia A and haemophilia B in the United States: results from the 2010 practice patterns survey. Haemophilia. 2012;18(3):e140-53.

24. Carcao M, Avila L, Blanchette VS, Santagostino E, Escuriola-Ettingshausen C, Leissinger CA, et al. Hemophilia prophylaxis no longer just for children without inhibitors - increasing use of prophylaxis in other groups (children with inhibitors and adults with and without inhibitors). Blood. 2015;126:3535.

25. Carcao M, Avila L, Aledort LM, Leissinger C. Prophylaxis practices in children and adults with hemophilia A or B and inhibitors. J Thromb Haemost. 2015;13:360.

26. Walsh CE, Soucie JM, Miller CH. United States Hemophilia Treatment Center Network. Impact of inhibitors on hemophilia A mortality in the United States. Am J Hematol. 2015;90(5):400-5.

27. O'Hara J, Hughes D, Camp C, Burke T, Carroll L, Garcia Diego D-A. The cost of severe haemophilia in Europe: the CHESS study. Orphanet J Rare Dis. 2017;12(106). https://doi.org/10.1186/s13023-017-0660-y.

28. Young G. New challenges in hemophilia: long-term outcomes and complications. ASH Hematol. 2012;1:362-8.

29. Leissinger $C$. Advances in the clinical management of inhibitors in hemophilia A and B. Sem Hematol. 2016:53:20-7.

30. Diamondstone LS, Aledort LM, Goedert JJ. Factors predictive of death among HIV-uninfected persons with haemophilia and other congenital coagulation disorders. Haemophilia. 2002;8(5):660-7.

31. Walsh CE, Soucie JM, Miller CH. Impact of inhibitors in hemophilia A mortality in the United States. Am J Hematol. 2015;90(5):400-5.

32. Tunstall $O$, Astermark J. Strategies for reducing inhibitor formation in severe haemophilia. Eur J Haematol. 2015;94(Suppl 77):45-50. 
33. Witmer C, Young G. Factor VIII inhibitors in hemophilia A: rationale and latest evidence. Ther Adv Hematol. 2013;4(1):59-72.

34. Berntorp E, Mauser-Bunschoten E, Jimenez-Yuste V, Spears JB. Comorbidities and inhibitors in adult patients with haemophilia: issues, costs and management strategies. Eur J Haematol. 2015;95(Suppl 80):1-15.

35. Pocoski J, Ma A, Kessler M, Boklage S, Humphries TJ. Cardiovascular comorbidities are increased in US patients with haemophilia A: a retrospective database analysis. Haemophilia. 2014;20:472-8.

36. Zanon E, lorio A, Rocino A, Artoni A, Santoro R, Tagliaferri A, et al. Intracranial haemorrhage in the Italian population of haemophilia patients with and without inhibitors. Haemophilia. 2012;18(1):39-45.

37. Schutgens RE, Klamroth R, Pabinger I, Malerba M, Dolan G. Atrial fibrillation in patients with haemophilia: a cross-sectional evaluation in Europe. Haemophilia. 2014;20(5):682-6.

38. Scalone L, Mantovani LG, Mannucci PM, Gringeri A. Quality of life is associated to the orthopaedic status in haemophilic patients with inhibitors. Haemophilia. 2006;12(2):154-62.

39. Gringeri A, Mantovani LG, Scalone L, Mannucci PM, COCIS Study Group: Cost of care and quality of life for patients with hemophilia complicated by inhibitors: the COCIS Study Group. Blood. 2003;102:2358-63.

Ready to submit your research? Choose BMC and benefit from:

- fast, convenient online submission

- thorough peer review by experienced researchers in your field

- rapid publication on acceptance

- support for research data, including large and complex data types

- gold Open Access which fosters wider collaboration and increased citations

- maximum visibility for your research: over $100 \mathrm{M}$ website views per year

At $\mathrm{BMC}$, research is always in progress.

Learn more biomedcentral.com/submissions 